${ }^{1}$ Dr. Shireen Afroz Associate Professor Dept. of Paediatric Nephrology Bangladesh Institute of Child Health \& Dhaka Shishu (Children) Hospital, Dhaka

Dr. Tahmina Ferdous

Medical Officer

Dept. of Paediatric Nephrology

Dhaka Shishu (Children) Hospital

3 Dr. Tania Sharmin

Dept. of Paediatric Nephrology

Dhaka Shishu (Children) Hospital

${ }^{4}$ Dr. Nasir Hossain

Assistant Professor

Dept. of Paediatric Nephrology

Dhaka Medical College Hospital

Correspondence

Dr. Shireen Afroz

Associate Professor

Dept. of Paediatric Nephrology

Bangladesh Institute of Child

Health \& Dhaka Shishu (Children)

Hospital, Dhaka

e-mail: safroz16@live.com

\title{
Aetiology and outcome of Hypernatremia in Post Diarrhoeal Acute Kidney Injury in Children- An Experience in Dhaka Medical College Hospital
}

\author{
S Afroz ${ }^{1}$, T Ferdous ${ }^{2}$, T Sharmin ${ }^{3}$, N Hossain ${ }^{4}$
}

\section{Abstract}

Background : Hypernatremia (serum sodium $150 \mathrm{mmol} / \mathrm{L}$ ) is one of the most life-threatening complications of childhood diarrhoea, Acute kidney injury(AKI) when associated with hypernatremia results increased mortality and long term morbidity.

Objectives : Our objective was to find out the aetiology and outcome of hypernatremia in post diarrhoeal AKI in children in a teaching hospital in Bangladesh.

Methods : This prospective observational study was conducted over 06 months in the Paediatric Nephrology Department of Dhaka Medical College Hospital.

A total of 15 children withpost diarrhoeal AKI withhypernatremia were evaluated.AKI staging was done by pRIFLE criteria. Hypernatremia was classified into mild, moderate and severe gradings. All patients were treated conservatively and with Intermittent Peritoneal Dialysis (IPD) as needed. Fluid adjustment was done according to serum sodium level.At the end of the study, samples were divided in to survive and death groups depending on outcome.

Results : Age of the children ranged from 2 months to 18months. Ninety three percent cases were under 1 year.Forty seven percent patients were in Failure stage of AKI, 47\%in Injury and 1 patient in Risk stage.Out of 15 cases $93 \%$ had severe hypernatremia. In $67 \%$ casesthe causes of hypernatremia were intake of concentrated oral rehydration solution (ORS) and found more in winter season. Regardless of cause overall $47 \%$ survived with normal renal functions and $53 \%$ died.

Conclusion : Intake of concentrated ORS and diarrhoea during winter seasona are the most important cause of hypernatremia in infancy. Hypernatremia with AKI stage III (Failure) had poorest outcome.

Key word : Acute kidney injury(AKI), Hypernatremia, Concentrated ORS.

Northern International Medical College Journal Vol. 8 No. 02 January 2017, Page 224-227

\section{Introduction}

The aetiology of AKI varies in different countries. ${ }^{1}$ In addition, the aetiology of AKI in hospitalized children is multifactorial. ${ }^{2}$ AKI may be divided into 3 categories: pre renal, renal, post renal. In contrast to developed countries, where AKI is more common in older children admitted to ICU with multiple co-morbidities and multiorgan failure, but AKI in children in developing countries, documented single disease entities such as diarrhoeal diseases, malaria, Haemolytic Uremic Syndrome (HUS) and acute glomerulonephritis as the major causes of AKI. ${ }^{3-6}$
Hypernatremia represents a deficit of water in relation to the body's sodium stores, which can result from a net water loss or a hypertonic sodium gain. Net water loss accounts for the majority of cases of hypernatremia. ${ }^{1,7}$ It can occur in the absenceof a sodium deficit (pure water loss) or in its presence (hypotonic fluid loss). Hypertonic sodium gain usually results from clinical interventions or accidental sodium loading. Because sustained hypernatremia can occur only when thirst or access to water is impaired, the groups at highest risk are patients with altered mental status, intubated patients, infants, and elderly persons. ${ }^{8}$ 
Hypernatremia in infants usually results from diarrhea, whereas in elderly persons it is usually associated with infirmity or febrile illness. ${ }^{9,10}$ Thirst impairment also occurs in elderly patients. ${ }^{11,12}$ Frail nursing home residents and hospitalized patients are prone to hypernatremia because they depend on others for their water requirements. ${ }^{13}$

This study was intended to find out the cause of hypernatremia in children presented with AKI and to find out their outcome in a tertiary care teaching hospital in Bangladesh.

\section{Methodology}

This observational study was carried out over a period of 6 months from November' 2013 to April' 2014, in the Department of Paediatric Nephrology, Dhaka Medical college and Hospital, Dhaka, Bangladesh. Written informed consent was obtained from each parents.

Inclusion criteria was, age ranges-> 1 month to 12 year of both sexes, those having sudden deterioration of Kidney function evidenced by- Paediatric RIFLE criteria of AKI staging ${ }^{14}$ and serum sodium more than $150 \mathrm{mEq} / \mathrm{L}$.

Exclusion criteria were AKI without hypernatremia, AKI on Chronic Kidney Disease. Hypernatremia was classified into mild, moderate and severe with serum sodium $150-155 \mathrm{mEq} / \mathrm{L}$, $>155-$ $170 \mathrm{mEq} / \mathrm{L},>170 \mathrm{mEq} / \mathrm{L}$ respectively. ${ }^{15}$

Hypotension was defined as systolic blood pressure less than 70 $\mathrm{mm} \mathrm{Hg}+2 \times$ age in years. Hypernatremia is frequently found in winter and to avoid cold the usual practice is giving less water in preparing ORS. ${ }^{16}$ Season of occurrence was considered winter from mid November to mid February and summer from mid February to April. When Oral Rehydration Salt was diluted in insufficient water less than $500 \mathrm{ml}$, was considered concentrated ORS.

\section{Paediatric RIFLE criteria of AKI staging ${ }^{14}$}

\section{Estimated creatinine clearance (eCCL) Urine output}

Risk (stage-1) eCCl decreased by $25 \%$

$<0.5 \mathrm{ml} / \mathrm{kg} / \mathrm{hr}$ for $8 \mathrm{hrs}$

Injury (stage-2) eCCl decreased by $50 \%$

$<0.5 \mathrm{ml} / \mathrm{kg} / \mathrm{hr}$ for $16 \mathrm{hrs}$

Failure (stage-3) eCCl decreased by $75 \%$

$<0.3 \mathrm{ml} / \mathrm{kg} / \mathrm{hr} 24 \mathrm{hrs}$ or anuria for $12 \mathrm{hrs}$

Loss (stage-4) Persistent failure for $>4$ weeks

End-stage (stage-5) Persistent failure $>3$ month

A total of 15 patients were admitted with post diarrhoeal AKI with hypernatremia during the study period. Patients with the features of AKI were clinically assessed. Detailed history was taken and thorough examinations were carried out and findings were noted. All patients were investigated thoroughly. Patients were managed conservatively (correction of fluid and electrolytes imbalance, correction of hypovolemia and shock, control of hypertension) or underwent IPD.

The indications for IPD were serum creatinine raised 3 fold from the baseline, urine output $<0.3 \mathrm{ml} / \mathrm{kg} / \mathrm{hr}$ for 24 hours or anuria for 12 hours, serum sodium $>180 \mathrm{mEq} / \mathrm{L}$ with evidence of symptomatic hypernatremia like encephalopathy, intractable severe metabolic acidosis, severe symptomatic hyperkalemia (serum $\mathrm{K}+>7 \mathrm{mEq} / \mathrm{L}$ ). Duration of IPD was 72 hours. But those who were on shock, their IPD was not performed immediately, usually done after improvement of shock.

Fluid adjustment was done according to serum sodium ( $\mathrm{Na}+$ ) level. The aim is to reduce the serum $\mathrm{Na}+$ by $10 \mathrm{mmol} / \mathrm{L}$ over the next 24 hours. Mild and moderate hypernatremia with dehydration but with normal serum potassium level were corrected by oral rehydration saline (ORS) through nasogastric tube connected to a microburrette. The amount of ORS was calculated by using following formula, amount of ORS: $\{10 \div$ $[(75-160) \div(0.6 \times$ wt in $\mathrm{kg}+1)]\}$ Litre/24 hour $=\mathrm{L} / 24 \mathrm{~h}=$ $\mathrm{ml} /$ hour. ${ }^{13,15}$ Intravenous fluid was given only when there was, shock, persistent vomiting ( 3 or more episodes per hour), high purging (stool output $>15 \mathrm{ml} / \mathrm{kg} /$ hour), paralytic ileus.

Severe hypernatremia with dehydration were managed with infusion of intravenous fluid with a difference of sodium level 10 $\mathrm{mEq} / \mathrm{L}$ from the patients serum $\mathrm{Na}$ (eg. when serum $\mathrm{Na}=$ $185 \mathrm{mEq} / \mathrm{L}$, infusate $\mathrm{Na}$ was maintained at $(185-10=) 175$ $\mathrm{mEq} / \mathrm{L}$.

The infusate fluid was prepared by adding various amounts of the $3 \% \mathrm{NaCl}$ in $5 \%$ dextrose in normal saline. To prepare this fluid we used (the amount of $3 \%$ normal saline that was added to $1 \mathrm{~L}$ of normal saline to make an IV solution that has the desired concentration of sodium was calculated from the) following equation:[1,000×(desired $\mathrm{Na}+154)] /(500$ desired $\mathrm{Na}+)=\mathrm{mL}$ of $3 \%$ normal saline. ${ }^{15}$

All the findings with aetiology and outcome of AKI and hypernatremia were noted in the data collection sheet and analyzed accordingly. Depending on final outcome patients were divided in to 2 groups, survived and died.

Data were processed by using software STATA 13. The test statistics used to analyze the data were Fisher's exact test and $t$ test, $\mathrm{p}$ value $<0.05$ was considered significant. 
Results

Table I : Sociodemographic characteristics $(n=15)$

$\begin{array}{lcccc}\text { Variables } & \text { Total \% } & \begin{array}{c}\text { Survived } \\ \mathbf{n = 0 7}\end{array} & \begin{array}{c}\text { Died } \\ \mathbf{n = 0 8}\end{array} \\ \text { Age } & <1 \text { year } & 14(93 \%) & 07 & 07 \\ \text { Sex } & >1 \text { year } & 01 & 00 & 01 \\ \text { Residence } & \text { Male } & 09 & 05 & 04 \\ & \text { Female } & 06 & 02 & 04 \\ \text { Socioeconomic status } & \text { Urban } & 07 & 02 & 05 \\ & \text { Rural } & 08 & 05 & 03 \\ \text { Maternal education } & \text { Urban slum } & --- & 00 & 00 \\ & \text { Poor } & 07 & 03 & 04 \\ & \text { Lower middle class } & 08 & 04 & 04 \\ & \text { Middle class } & 00 & 00 & 00 \\ & \text { IIliterate } & 06 & 02 & 04 \\ & \text { Primary class-V } & 06 & 03 & 03 \\ & \text { SSC } & 03 & 02 & 01 \\ & \text { HSC } & 00 & 00 & 00 \\ & \text { College/university } & 00 & 00 & 00\end{array}$

Age of the children ranged from 2 months to 18months. Out of 15 children 14 (93\%) were under 1 year and only 1 was older than 1 year. Among them, 09 were male and 06 were female, $\mathrm{M}: \mathrm{F}=1.5: 1$. Fifty percent patients were from rural and $50 \%$ from urban areas. Most of them were from poor and lower middle class socioeconomic status. Most of the mother was illiterate. The overall $7(47 \%)$ survived with normal renal functions and $8(53 \%)$ died.

\begin{tabular}{lcccc}
\multicolumn{4}{l}{ Table II : Presenting complaint of the study children } \\
$\begin{array}{l}\text { Presenting } \\
\text { complaints }\end{array}$ & $\begin{array}{c}\text { Total } \\
(\mathbf{n 0}=\mathbf{1 5})\end{array}$ & $\%$ & $\begin{array}{c}\text { Survived } \\
(\mathbf{n}=\mathbf{0 7})\end{array}$ & $\begin{array}{c}\text { Death } \\
(\mathbf{n}=\mathbf{0 8})\end{array}$ \\
Convulsion & 14 & $(93 \%)$ & 07 & 07 \\
Vomiting & 10 & $(67 \%)$ & 04 & 06 \\
Severe dehydration & 10 & $(67 \%)$ & 03 & 07 \\
Anuria & 08 & $(53 \%)$ & 03 & 05 \\
Fever & 07 & $(47 \%)$ & 02 & 05 \\
Oliguria & 07 & $(47 \%)$ & 03 & 04 \\
Respiratory difficulty & 07 & $(47 \%)$ & 03 & 04 \\
Hypovolemic Shock & 05 & $(33 \%)$ & 01 & 04
\end{tabular}

The major clinical presentation was convulsion (93\%), followed by vomiting, severe dehydration, oliguria, anuria, fever and shock.

Table III : AKI staging $(n=15)$

AKI staging Total No. (15) \%

$\begin{array}{lllll}\text { Risk (R) } & 01 & (06 \%) & 01 & 00 \\ \text { Injury (I) } & 07 & (47 \%) & 05 & 02 \\ \text { Failure (F) } & 07 & (47 \%) & 01 & 06\end{array}$

Forty seven percent $(n=7)$ patients were in Failure stage of AKI, $47 \%(n=7)$ in Injury and 1 patient was in Risk stage. Majority of death $(n=6)$ was found in
Failure stage.

Table IV: Aetiologyof hypernatremia $(n=15)$

Causes of Total $(n=15) \%$ Survived $(n=7) \quad$ Death $(n=8) \quad p$ value ( $F$ test) hypernatremia

Concentrated ORS

$\begin{array}{lllll}10 & (67 \%) & 05 & 05 & 1.000\end{array}$

$\begin{array}{llllll}\text { Concentrated formula } & 02 & (13 \%) & 01 & 01 & 1.000\end{array}$

Salt or salty drugs in $\quad 01 \quad(7 \%) \quad 00 \quad 01 \quad 1.000$

food or drink

$\begin{array}{llllll}\text { Unknown } & 01 & (7 \%) & 01 & 00 & 0.467\end{array}$

$\begin{array}{lllll}\text { IV Normal saline infusion } 01 & (7 \%) & 00 & 01 & 1.000\end{array}$

Season of occurrence(giving less amount of water to make ORS and also to the child to avoid cold)

$\begin{array}{llllll}\text { Winter } & 10 & 67(\%) & 05 & 05 & 1.000\end{array}$

$\begin{array}{llllll}\text { Summer } & 05 & 33(\%) & 02 & 03 & 1.000\end{array}$

$\mathrm{F}$ test $=$ Fisher's exact test.

In $67 \%(n=10)$ cases the cause of hypernatremia was intake of concentrated ORS. About $67 \%$ cases were found in winter season. But none of the factors are statistically significant.

Table V : Severity of hypernatremia $(n=15)$

Total $(n=15) \quad \% \quad$ Survived $(n=07) \quad$ Death $(n=08)$

Mild (serum $\mathrm{Na}=150-155$

$\begin{array}{llll}\mathrm{mEq} / \mathrm{L}) & 00 & 00 & 00\end{array}$

Moderate

$\begin{array}{lllll}\text { (serum Na }>155-170 \mathrm{mEq} / \mathrm{L}) & 01 & (07 \%) & 01 & 0\end{array}$

Severe

$\begin{array}{lllll}\text { (serum } \mathrm{Na}>170 \mathrm{mEq} / \mathrm{L}) & 14 & (93 \%) & 06 & 08\end{array}$

Mean serum sodium level

$(\mathrm{mEq} / \mathrm{L})$ on admission

180.32

177.28

183.37

Mean serum sodium level

(mEq/L) on discharge/

at the time of death

158.65

147.2

170.1

Out of 15 cases $14(93 \%)$ had severe hypernatremia. The mean serum sodium level at the time of admission was $177.28 \mathrm{mEq} / \mathrm{L}$ Vs $183.37 \mathrm{mEq} / \mathrm{L}$ in survived and death cases respectively. The mean serum sodium at the time of discharge was $147.2 \mathrm{mEq} / \mathrm{L}$ in survived patients, and at the time of death was $170.1 \mathrm{mEq} / \mathrm{L}$.

\section{Discussion}

In this study the age of the children ranged from 2 months to 18 months and out of 15 children 14 were under 1 year. It suggests that the young infants are more prone to hypernatremia because they depend on caregivers for their feeding and water requirements. ${ }^{8,13}$ Majority were from a poor and lower middle class socioeconomic status. Most of the mother was illiterate. In $67 \%$ cases the cause of hypernatremia was intake of concentrated ORS. About 67\% occurrence was found in winter season. It stresses that illiteracy and ignorance are the most important causes of improper mixing of ORS in this series. Faulty 
thoughts of giving less water during winter to avoid cough and cold is another reason behind it. Improperly prepared ORS often been reported to cause different degrees of hypernatremia.

Childhood diarrhea caused by rotavirus infection often presents with watery stools, which is associated with the body's conservation of sodium loss via stools. Consumption of appropriately prepared ORS in rotavirus-caused diarrhea may still result in a hyperosmolar condition. Children become excessively thirsty, which often results in caregivers' frequently administering ORS to quench thirst and ultimately leads to severe and extreme hypernatremia. ${ }^{16}$

Similar to this study, hypernatremia was found more frequent in winter. ${ }^{16}$ Several studies showed thatless important care given for hydration in winter than in summer, during that time a higher infection rate in winter. In the present study we also found that during winter ORS prepared with less amount of water and also give less water to the child to avoid cold). Our study results also consistent with the previous studies. ${ }^{10,13}$

Out of 15 cases $14(93 \%)$ had severe hypernatremia and amongst them 8 died. In this study, we did not find a statistical link between the factors like young age of occurrence, the severity of hypernatremia, severity of AKI, convulsion, use of concentrated ORS and mortality. The small cohort size also probably explains why the relationship between hypernatremia and death did not reach statistical significance. Previous study also had similar conclusion. ${ }^{17}$

The major clinical presentations were convulsion (93\%), followed by vomiting, severe dehydration, oliguria, anuria, fever and shock. Acute watery diarrhoea with severe dehydration was found as an important cause of AKI in Bangladesh. ${ }^{18}$ Poor socioeconomic status, lack of food hygiene, poor hand washing before meal, lack of health education and public awareness is responsible for this in our country. ${ }^{18}$

The mortality in AKI in children has been reported to vary widely from $16 \%$ to $43.8 \% .4,8,10$ In the present study, mortality rate was $53 \%$, which is comparable to a recent study from Kuwait reporting $43.8 \%$ mortality. ${ }^{8}$ A retrospective study of 311 children with ARF over a 22 years period from Thailand reported mortality as $41.5 \% .{ }^{19}$ Much of the data on incidence and mortality of AKI are limited to the developed world.

Neurological symptoms are frequent in hypernatremia caused by the hyperosmolar effect of hypernatremia itself and we report that $67 \%$ of patientshad convulsion at admission.

\section{Conclusion}

Intake of concentrated ORS and diarrhoea during winter season are the most important cause of hypernatremia in infancy.
Hypernatremia with AKI stage III (Failure) results worst outcome.

\section{Study limitations and recommendations}

This is a small sampled, single centre study and long term neurological outcomes of study subjects were not seen. Therefore, a large multicentre observational study is needed.

\section{References}

1. Palevsky PM. Hypernatremia. In: Greenberg A, ed. Primer on Kidney Diseases. Second ed. San Diego, Calif.: Academic Press, 1998:175-200.

2. Andreoli SP. Acute kidney injury in children. PediatrNephrol. 2009; 24(2):253-63.

3. Hui-Stickle S, Brewer ED, Goldstein SL. Pediatric ARF epidemiology at a tertiary care center from 1999 to 2001. Am J Kidney Dis. 2005;45(1):96-101.

4. Bailey D, Phan V, Litalien C, Ducruet T, Merouani A, et al. (2007) Risk factors of acute renal failure in critically ill children: A prospective descriptive epidemiological study. PediatrCrit Care Med 8: 29-35.

5. Assounga AG, Assambo-Kieli C, Mafoua A, Moyen G, NzingoulaS Etiology and outcome of acute renal failure in children in congo-brazzaville. Saudi J Kidney Dis Transpl 2000, 11: 40-43.

6. Van Biljon $\mathrm{G}$ Causes, prognostic factors and treatment results of acute renal failure in children treated in a tertiary hospital in South Africa. J Trop Pediatr 2008, 54: 233-237.

7. Gennari FJ, Kassirer JP. Osmotic diuresis. N Engl J Med 1974; 291:714-20.

8. Gennari FJ. Hypo-hypernatraemia: disorders of water balance. In: Davison AM, Cameron JS, Grünfeld J-P, Kerr DNS, Ritz E, Winearls CG, eds. Oxford textbook of clinical nephrology. 2nd ed. Vol. 1. Oxford, England: Oxford University Press, 1998:175-200.

9. Finberg L, Harrison HE. Hypernatremia in infants: an evaluation of the clinical and biochemical findings accompanying this state. Pediatrics 1955; 16:1-14.

10. Bruck E, Abal G, Aceto T Jr. Pathogenesis and pathophysiology of hypertonic dehydration with diarrhea: a clinical study of 59 infants with observations of respiratory and renal water metabolism. Am J Dis Child 1968; 115:122-44.

11. Phillips PA, Bretherton M, Johnston CI, Gray L. Reduced osmotic thirst in healthy elderly men. Am J Physiol 1991; 261:R166-R171.

12. Silver AJ, Morley JE. Role of the opioid system in the hypodipsia associated with aging. J Am GeriatrSoc 1992; 40:556-60.

13. Androgue HJ, Madias NE. Hypernatremia. N Engl J Med 2000;342 :14931499

14. Akcan-Arikan A, Zappitelli M, Loftis LL. Modified RIFLE criteria in critically ill children with acute kidney injury, Kidney Int., 2007; 71: 1028-35.

15. Schwaderer AL, Schwartz GJ. Treating Hypernatremiac Dehydration. Pediatrics In Review- AAP News. 2005; 26(4).

16. Sumon Kumar Das, FarzanaAfroze, Tahmeed Ahmed, Abu Syed Golam Faruque, ShafiqulAlamSarker, SayeedaHuq, M Munirul Islam, LubabaShahrin, FarihaBushraMatin, and MohammodJobayerChisti. Extreme hypernatremic dehydration due to potential sodium intoxication: consequences and management for an infant with diarrhea at an urban intensive care unit in Bangladesh: a case report. J Med Case Rep. 2015; 9: 124

17. Bataille $S$, Baralla $C$, Torro D, Buffat $C$ et al.Undercorrection of hypernatremia is frequent and mortality. BMC Nephrology 2014;15:37

18. Afroz S, Simi MA, Sharmim S, Khanum R, Yeasmin L, Kundo LC et al. Aetilogy and Outcome of Acute Kidney Failure in Bangladeshi Children- Dhaka Medical College Hospital Experienncel. JDMCH; 2016(24):86-91

19. Vachvanichsanong $P$, Dissaneewate $P$, Lim A, McNeil E. Childhood acute renal failure: 22-year experience in a university hospital in southern Thailand. Pediatrics. 2006;118(3):e786-91. 